research projects may be difficult with an expectation that a project will be devised and written up in six months.

One suggestion has been that allocation should be decided by the rotation tutor after consultation with each trainee; however, this will inevitably lead to complaints of unfairness. Perhaps more than one post should be allocated at a time as this would make planning for research and psychotherapy easier. But unpredictability of failure in the MRCPsych exams makes this difficult. An amalgamation of these two alternatives together with the present system may prove most appealing to all.

Experiences in other training schemes might be profitably shared.

ToM MCClintock Chairman Psychiatric Trainees

Springfield Hospital

61 Glenburnie Road

London SWI7

\section{Welfare workers reaching out across the poverty gap}

DeAr Sirs

As unemployment in Britain reaches levels seen in the Great Depression of the 1930s, mental health care within the National Health Service and local authority social services is also under-going rapid change. We have been reconsidering access to welfare advice for patients of the Special Health Authority. "Social decline" (Jones et al, 1993) against a background of "social deprivation" (Thornicroft, 1991) is characteristic of our severely mentally ill clientele. Poverty often coexists with social disability related to mental illness, and it is evident (Leary et al, 1991) that the majority of such patients have difficulty seeking or gaining support by themselves. Feeding back through several channels (Caan, 1993), patients with limited resources or social support identified a lack of information about welfare rights and few sources of advice as major concerns. Welfare workers are a potential source of advice, and the Welfare Rights Unit identified a need to adapt provision of such advice to our clients. For example, the new Disability Living Allowance can have a big impact on patients (typically doubling their income), but its complexity means that considerable interprofessional liaison is necessary for each case and an experienced welfare worker requires over one hour to complete the forms. The process of gaining access to this allowance can be upsetting to patients, without skilled advocacy and facilitation, because of its negative focus on an individual's handicap.
To make access to advocacy and facilitation more comprehensive, rather than just reacting to the most vocal patients, the six welfare workers undertook a proactive "outreach" to all psychiatric in-patients across the Bethlem Royal and Maudsley Hospitals, for six months (July-December 1992). The impact of the new outreach style was evaluated by an independent auditor and compared with five six monthly periods between January 1990 and June 1992. A random sample of 100 admissions (from the Patient Administration System data) was investigated for each six month period. Prior to the outreach, only 200 out of 500 admissions had access to the welfare team $(40 \%)$. The delay between admission and first contact with welfare officers was extremely variable (0-123 days) and rising with time (the regression slope was 1.57 days per six month period). A standard was then set that everyone should be assessed for need by their sixth week of admission, and every ward visited weekly by one welfare worker, who became a regular member of that ward's "multidisciplinary team".

Throughout the six months of outreach, delays to assessment of need and variability of this waiting time were reduced. For example, the mean wait in July-December 1991 was 21.6 days, which fell to a mean of 12.6 days during the same period in 1992 $(P=0.023)$, and the waiting became much less variable $(P=0.0036)$. Overall in the preceding 2.5 years, $5.1 \%$ of patients waited over seven weeks for contact (if they received any advice at all) whereas none waited as long as seven weeks after July 1992. Before outreach, the majority of in-patients did not have access to this service. The rate of contact rose with outreach, until by 30 December the active caseload was 430, compared with a bed occupancy of 372 on Christmas day. Achieving this contact, in excess of $100 \%$ of the in-patients, was due in part to the active follow-up users who had just been discharged over the recent holiday period. A satisfaction survey of in-patient wards had shown that 73 out of $90,81 \%$ of patients found the welfare officers "helpful" or "very helpful" (compared to 644 out of 868 [74\%] of responses about the helpfulness of nine other mental health professions in the hospital). An objective corollary of this reported helpfulness to users was the identification of needs. Monthly rates of arranging support increased (e.g. clothing grants averaged $212 \%$ and loans $202 \%$ of last year's levels). Backed by a training programme, welfare workers now have clearer expectations of their roles (e.g. in planning ahead for discharges) and time can be freed for, say, the qualified social workers' specific mental health roles.

In conclusion, many patients had previously "slipped through the net" of welfare help. This may apply to other psychiatric hospitals and figure prominently in the hierarchy of needs during mental 
illness. It is possible to address such basic needs systematically and so facilitate the operation of caring services in promoting mental health.

WOODY CAAN

Audit Team

Carol Waylett

The Maudsley Hospital

Welfare Rights Unit

London SE5 8AZ

\section{References}

CAAN, W. (1993) Case or consumer? The value of patient feedback to mental health services. In Clinical Audit 1993, pp. 13-14. London Department of Health.

Jones, P. B., Bebrington, P., Foerster, A. et al (1993) Premorbid social underachievement in schizophrenia. British Journal of Psychiatry, 162, 65-71.

LeARY, J., JOHNSTONE, E. C. \& OWENS, D. G. C. (1991) Social outcome. British Journal of Psychiatry, 159, (suppl. 13), 13-20.

ThORNiCroft, G. (1991) Social deprivation and rates of treated mental disorder. British Journal of Psychiatry. $158,475-484$.

\section{'Out of working hours' emergencies with learning disabilities}

DeAr Sirs

Typically it is a Saturday afternoon. An 'on-call' general medical practitioner has been called urgently to the residence of a young man with learning disability, either his own family home or a community house. His parents or carers say he has "gone berserk" and is "out of control". He has been smashing everything in his own room, or breaking up the house, throwing objects at the people there, or aggressively hitting out at those around him.

The doctor who has been called finds the parents or carers are feeling distraught, frightened and helpless. Unable to obtain Social Service Department support, the doctor telephones the consultant psychiatrist for learning disabilities and requests admission to hospital. Attempts to temporise by giving the patient sedation or neuroleptic drugs and by counselling the patient and carers usually fail as, after the doctor has gone, a resurgence of the violence, anxiety and distress often occurs within a few hours.

In 28 years as a consultant I have seen this sequence often enough for it to be a "Saturday afternoon syndrome". In the past, admission to a hospital was generally easy to arrange, but is now increasingly a matter of prolonged negotiation, delay, and even acrimony, as NHS units for learning disabilities are run down or disappear. Usually, social services facilities have neither the vacancy nor the staff to cope with such a patient. The police are hesitant to act, preferring to see it as a medical responsibility.
The removal of the patient from his residence to hospital is the inevitable practical solution. Frequently the patient can be persuaded to go into hospital informally where he usually settles down and within a few days is welcomed back home.

General practitioners and consultant psychiatrists are often asked to assist in cases of acutely disturbed people with learning disabilities. Purchasers and providers need to be aware of the requirement to have specific provision for emergency short-term respite care for the assessment and treatment of people with learning disabilities as part of a comprehensive community service.

Meanwood Park Hospital

D. A. SPENCER Leeds LS6 $4 Q B$

\section{Cognitive behavioural psychotherapy}

\section{Dear SiRS}

While welcoming Stern's call for psychiatrists to have greater training in cognitive-behavioural psychotherapy (Psychiatric Bulletin, January 1992, $17,1-4)$ we were surprised at the suggestion that "psychologists are waiting in the wings in this country but already therapeutically active in the USA" in respect of this treatment. This model of treatment has long been in the mainstream of clinical psychology and, for many clinical psychologists in the UK, it is a familiar and frequently used approach. A recent survey of clinical psychologists found that $48 \%$ of British clinical psychologists come from the behavioural and cognitive traditions as opposed to $29 \%$ of US clinical psychologists.

We feel well placed to provide such therapy and to train and supervise other professionals as our first degree course provides a sound basis in learning theory and cognitive psychology and our three year post-graduate clinical training course includes extensive training in the application of the cognitive - behavioural approach.

\section{MARIE QuAYLE PETER SCRAGg on behalf of the Broadmoor Clinical Psychology Department}

Broadmoor Hospital Crowthorne, Berkshire RG11 7EG

\section{Reply}

Dear Sirs

It should be remembered that my article was written for the Psychiatric Bulletin with psychiatrists in mind. I did not mean to diminish in any way the sterling work done by psychologists in the field of behavioural and cognitive psychotherapy in this country. I personally have always enjoyed working alongside psychologists. 